\title{
Prevalence, predictors, and outcomes of poststroke falls in acute hospital setting
}

Arlene A. Schmid, PhD, OTR; ${ }^{1-3 *}$ Carolyn K. Wells, MPH; ${ }^{4}$ John Concato, MD; ${ }^{4-6}$ Mary I. Dallas, PT, PhD; ${ }^{5}$ Albert C. Lo, MD, PhD; $;^{7-8}$ Steven E. Nadeau, MD; ${ }^{9-10}$ Linda S. Williams, MD; ${ }^{1,3,11-12}$ Aldo J. Peixoto, MD; ${ }^{5-6}$ Mark Gorman, MD; ${ }^{13}$ John L. Boice, MD; ${ }^{14}$ Frederick Struve, PhD; ${ }^{4}$ Vincent McClain, MD; ${ }^{4}$ Dawn M. Bravata, $\mathrm{MD}^{1,12,15}$

${ }^{1}$ Department of Veterans Affairs (VA) Health Services Research and Development (HSR\&D) Center of Excellence on Implementing Evidence-Based Practice and HSR\&D Stroke Quality Enhancement Research Initiative, Richard L. Roudebush VA Medical Center (VAMC), Indianapolis, IN; ${ }^{2}$ Department of Occupational Therapy, Indiana University School of Health and Rehabilitation Sciences, Indianapolis, IN; ${ }^{3}$ Indiana University Center for Aging Research, Indianapolis, IN; ${ }^{4}$ Clinical Epidemiology Research Center, VA Connecticut Healthcare System, West Haven, CT; ${ }^{5}$ VA Connecticut Healthcare System, West Haven, CT; ${ }^{6}$ Department of Internal Medicine, Yale School of Medicine, New Haven, CT; ${ }^{7}$ Departments of Neurology, Engineering, Neuroscience, and Community Health, Warren Alpert Medical School of Brown University, Providence, RI; ${ }^{8}$ Providence VAMC, Providence, RI; ${ }^{9}$ Neurology Service, Malcom Randall VAMC, Gainesville, FL; ${ }^{10}$ Department of Neurology, College of Medicine, University of Florida, Gainesville, FL; ${ }^{11}$ Department of Neurology, Indiana University School of Medicine, Indianapolis, IN; ${ }^{12}$ Regenstrief Institute, Inc, Indianapolis, IN; ${ }^{13}$ Department of Neurology, University of Vermont College of Medicine, Burlington, VT; ${ }^{14}$ Medicine Service, Boise VAMC, Boise, ID; ${ }^{15}$ Department of Internal Medicine, Indiana University School of Medicine, Indianapolis, IN

\begin{abstract}
Falls are a serious medical complication following stroke. The objectives of this study were to (1) confirm the prevalence of falls among patients with stroke during acute hospitalization, (2) identify factors associated with falls during the acute stay, and (3) examine whether in-hospital falls were associated with loss of function after stroke (new dependence at discharge). We completed a secondary analysis of data from a retrospective cohort study of patients with ischemic stroke who were hospitalized at one of four hospitals. We used logistic regression to identify factors associated with inpatient falls and examine the association between falls and loss of function. Among 1,269 patients with stroke, 65 (5\%) fell during the acute hospitalization period. We found two characteristics independently associated with falls: greater stroke severity (National Institutes of Health Stroke Scale [NIHSS] $\geq 8$, adjusted odds ratio $[\mathrm{OR}]=3.63,95 \%$ confidence interval $[\mathrm{CI}]$ : 1.46-9.00) and history of anxiety (adjusted OR $=4.90,95 \%$ CI: 1.70-13.90). Falls were independently associated with a loss of function (adjusted OR $=9.85,95 \%$ CI: 1.22-79.75) even after adjusting for age, stroke severity, gait abnormalities, and past stroke. Stroke severity (NIHSS >8) may be clinically
\end{abstract}

useful during the acute inpatient setting in identifying those at greatest risk of falling. Given the association between falls and poor patient outcomes, rehabilitation interventions should be implemented to prevent falls poststroke.

\footnotetext{
Abbreviations: ADL $=$ activity of daily living, $\mathrm{CI}=$ confidence interval, IADL = instrumental activity of daily living, NIHSS = National Institutes of Health Stroke Scale, OR = odds ratio, $\mathrm{SD}=$ standard deviation, TIA = transient ischemic attack, UTI = urinary tract infection, VA = Department of Veterans Affairs.

*Address all correspondence to Arlene A. Schmid, PhD, OTR; Center of Excellence on Implementing EvidenceBased Practice, Richard L. Roudebush VAMC, HSR\&D Mail Code 11H, 1481 W 10th St, Indianapolis, IN, 46202; 317-988-3480; fax: 317-988-3222.

Email: arlene.schmid@va.gov

DOI:10.1682/JRRD.2009.08.0133
} 
Key words: activities of daily living, falls, function, functional status, outcomes, predictors, prevalence, stroke, stroke recovery, stroke severity.

\section{INTRODUCTION}

Approximately 795,000 people sustain a stroke in the United States each year [1]. The negative stroke sequelae and high prevalence make stroke the most commonly treated disability by rehabilitation therapists [2]. Patients with stroke often have persistent neural deficits related to changes in motor function and sensation [3], which can increase their risk of falling [4-5]. Falls are a serious medical complication after stroke [6]. Up to 75 percent of patients with stroke fall during the first 6 months poststroke [4] compared with the 30 percent annual fall rate in the general (nonstroke) older adult population [7].

Fall-related consequences for the older adult can be severe and include hip fractures, head trauma, increased healthcare use, increased admissions to long-term care facilities, premature disability (including restricted activity days), and death [8-10]. Tinetti and Williams demonstrated a robust association between fall frequency and declines in both activity of daily living (ADL) and instrumental ADL (IADL) functioning [11]. Falls after stroke may further contribute to poststroke dependence in ADLs and IADLs and decreased participation in society [6]. Hyndman and Ashburn demonstrated a relationship between stroke, falls, and ADL functioning in poststroke adults who are residing in the community [12]. Additionally, poststroke falls are related to increased risk of poststroke depression [13] and hip fracture (often of the hemiparetic limb) [14].

Fall risk factors are numerous and fall risk is often considered to be multifactorial in the general older adult population [15]. Fall risk increases as the number of risk factors increases [16]. In a recent review of neurologically related fall risk factors, Thurman et al. found a strong association between stroke and fall risk [17].

While fall risk has been studied in the poststroke rehabilitation period [18-22] and often after discharge home and into the community [4-5,13,23-25], little is known about poststroke falls in the acute hospital inpatient setting. A recent review of fall risk factors [17] included only one study that examined falls among patients with stroke still in the acute hospital inpatient setting: Tutuarima et al. reported a relationship among nursing care, patient cognitive changes, and falls [26].
However, some studies that focused on poststroke safety and complications have identified increased fall risk during the poststroke acute hospitalization. For example, Davenport et al. reported falls to be the most common medical complication after stroke [6] and Holloway et al. found a 6 percent falls rate after stroke in the acute setting [27]. Falls and other medical complications were associated with triple the length of the acute hospital stay.

Our study objectives comprised (1) confirming the prevalence of falls among patients with stroke in the acute hospital inpatient setting, (2) identifying the predictive factors associated with poststroke falls during the acute stay, and (3) examining whether in-hospital falls are associated with dependence in ADLs after stroke.

\section{METHODS}

We performed a secondary analysis of data derived from a retrospective cohort study that evaluated medical records through chart review of patients with an ischemic stroke or transient ischemic attack (TIA) admitted to one of two Department of Veterans Affairs (VA) or one of two non-VA hospitals between 1998 and 2003 [28]. We included veterans and nonveterans in the original parent study if they had an acute ischemic stroke or TIA, had neurological symptom onset within 2 days of admission, had a neurological deficit on admission (National Institutes of Health Stroke Scale [NIHSS] $\geq 2$ ), and were $\geq 18$ years old. We excluded patients if they were residing in a skilled nursing facility at the time of the stroke symptom onset, were already admitted to the hospital at the time of the stroke symptom onset, were transferred from another acute care facility, or were not admitted to the hospital.

We included only patients with stroke in the current analysis. Within the original data set, we excluded comatose patients with stroke as they are not at risk for falls and patients with TIA because they are unlikely to fall in relation to TIA. We also excluded patients who resided in a nursing facility at the time of their stroke onset because their fall risks are likely different than those of someone not living in a facility [29].

Demographic data included age, race, and sex. We included length of stay for poststroke acute inpatient hospitalization. We included comorbidity information as individual comorbidities as well as a Charlson Comorbidity index [30]. Comorbidities of interest included a history of prior stroke or TIA, hypertension, depression, anxiety, 
diabetes, diabetes with nerve disease, seizures, syncope, urinary tract infections (UTIs), and Parkinson disease. We chose these comorbidities as all are documented fall risk factors [10]. We considered each comorbidity to exist if we found any history of the comorbidity in the progress notes of the medical record. For example, if progress notes listed depression or anxiety in the past medical history, then we included these items as a comorbidities in the chart review. We did not include additional criteria for specific diagnoses.

We completed brain imaging, allowing us to include stroke location information in our analyses. We also included medications (individually and categorized) as variables of interest because medications and polypharmacy are commonly documented fall risk factors [10,31]. We included blood pressure medications, sedatives, antipsychotics, and multiple categories of medications (narcotics, opioids, benzoids, and tricyclics).

\section{Falls}

We considered any fall documented within any area of the medical record (nursing, doctor, rehabilitation, etc.) a fall for this study. We defined patients with a single fall or multiple falls occurring at any time during the acute hospital inpatient stay as having a fall. The chart abstraction form simply asked "fall during hospitalization" and the chart reviewer documented it as a fall if any fall was documented at any time during the stay.

\section{Stroke Severity}

We used a retrospective NIHSS [32-33] to assess stroke severity [34]. The elements to complete the retrospective NIHSS can be found in most medical charts. The NIHSS is an 11-item scale that includes consciousness, vision, language, sensory, ataxia, and arm and leg motor function. The retrospective NIHSS is a valid and reliable scale [34-35]. Increasing scores represent increasing stroke severity. We excluded those with an NIHSS $\geq 18$ because patients with such severe strokes are unlikely to be mobile and are therefore unlikely to fall.

We categorized patients as having mild stroke (NIHSS $<8$ ) or moderate-severe stroke (NIHSS $\geq 8$ ). We chose an NIHSS $\geq 8$ as the cutoff based on the work of Clark et al., who previously found an NIHSS $<8$ to describe patients with milder stroke [36].

In addition to the total NIHSS score, we examined individual neurological symptoms for their association with fall risk, including hemiparesis (no drift vs any drift or no movement), sensory loss (no sensory loss vs mild, moderate, severe, or total loss), ataxia (absent vs present), and aphasia (absent vs present). We also classified gait as either normal or abnormal (walking or balance dysfunction of any kind identified in the chart review).

\section{Functional Status}

We used medical record documentation about feeding, toileting, transferring, bathing, grooming, walking, and/or dressing to code prestroke functional status as either independent or dependent. If the medical record indicated that the patient needed assistance with any ADL (e.g., bathing) then we defined the patient as dependent. We similarly coded functional status at the time of discharge from the acute hospital inpatient stay. We considered patients who were independent prestroke and dependent at discharge to have a loss of functional status for this analysis. We did not use documentation about IADLs (e.g., managing money) to code functional status.

\section{Statistical Analysis}

We completed all analyses using SPSS statistical software version 17.0 (SPSS, Inc; Chicago, Illinois). We used mean \pm standard deviation (SD) or frequencies and proportions to describe the baseline characteristics of the cohort and the outcome rates. We evaluated the baseline factors that were potentially associated with falls in bivariate analyses using chi-square or Student $t$-tests. We included medications both as categories and as separate medications.

To identify the factors that were independently associated with falls, we constructed a multivariate logistic regression model that used backward elimination to model fall risk that included those factors that were associated with falls in the bivariate analysis $(p<0.05)$ and those that were identified by a priori clinical judgment (gait abnormality and Charlson Comorbidity index).

To examine the association between inpatient falls and a loss of functional status, we used the same multivariable analytic approach, this time modeling loss of function. We maintained an event-per-variable ratio of 10:1 (at least 10 individuals for each variable) in the multivariable models [37]. We set the level of statistical significance at $p<0.05$. We made no imputations for missing data. We calculated the impact factor to rank the association between independent variables (e.g., stroke severity) and the dependent variable (e.g., falls) $\left(R^{2}=\right.$ Wald chi-square - 2/-2 $\ln \mathrm{L}_{\mathrm{o}}$ ) [38]. 
JRRD, Volume 47, Number 6, 2010

\section{RESULTS}

Table 1 presents the characteristics of the 1,269 patients with stroke. The majority of the participants were male (56\%) and aged $71.21 \pm 13.30$ years (mean \pm SD). Of the participants, 202 (16\%) were African American and 570 (45\%) had moderate to severe strokes (NIHSS $\geq 8$ ).

\section{Falls}

The prevalence of falls during the acute hospital inpatient period was 5 percent $(65 / 1,269)$. Patients who fell were more likely to have moderate to severe strokes ( $57 \%$ vs $44 \%, p=0.03$ ), have a past medical history of anxiety ( $20 \%$ vs $8 \%, p<0.001)$, and a history of UTIs
(25\% vs $15 \%, p=0.05$ ) than patients who did not fall (Table 1). We found no difference in length of stay between fallers and nonfallers ( $p=0.32$ ). We also found no differences in medication use, either by category or individual drugs among those who did or did not fall (data not shown).

Table 2 presents the adjusted odds ratio (OR) and 95\% confidence interval (95\% CI) from the first multivariable analysis. We included stroke severity, gait abnormalities, the Charlson Comorbidities index, history of anxiety, and history of UTI in the model. Two characteristics were independently associated with poststroke falls: moderate to severe stroke severity (NIHSS $>8$ ) (adjusted OR $=3.63$, 95\% CI: 1.46-9.00) and history of anxiety (adjusted OR =

Table 1.

Baseline characteristics and association with poststroke falls during acute hospital inpatient stay. $N=$ total group, $n=\operatorname{subgroup}(\mathrm{s})$.

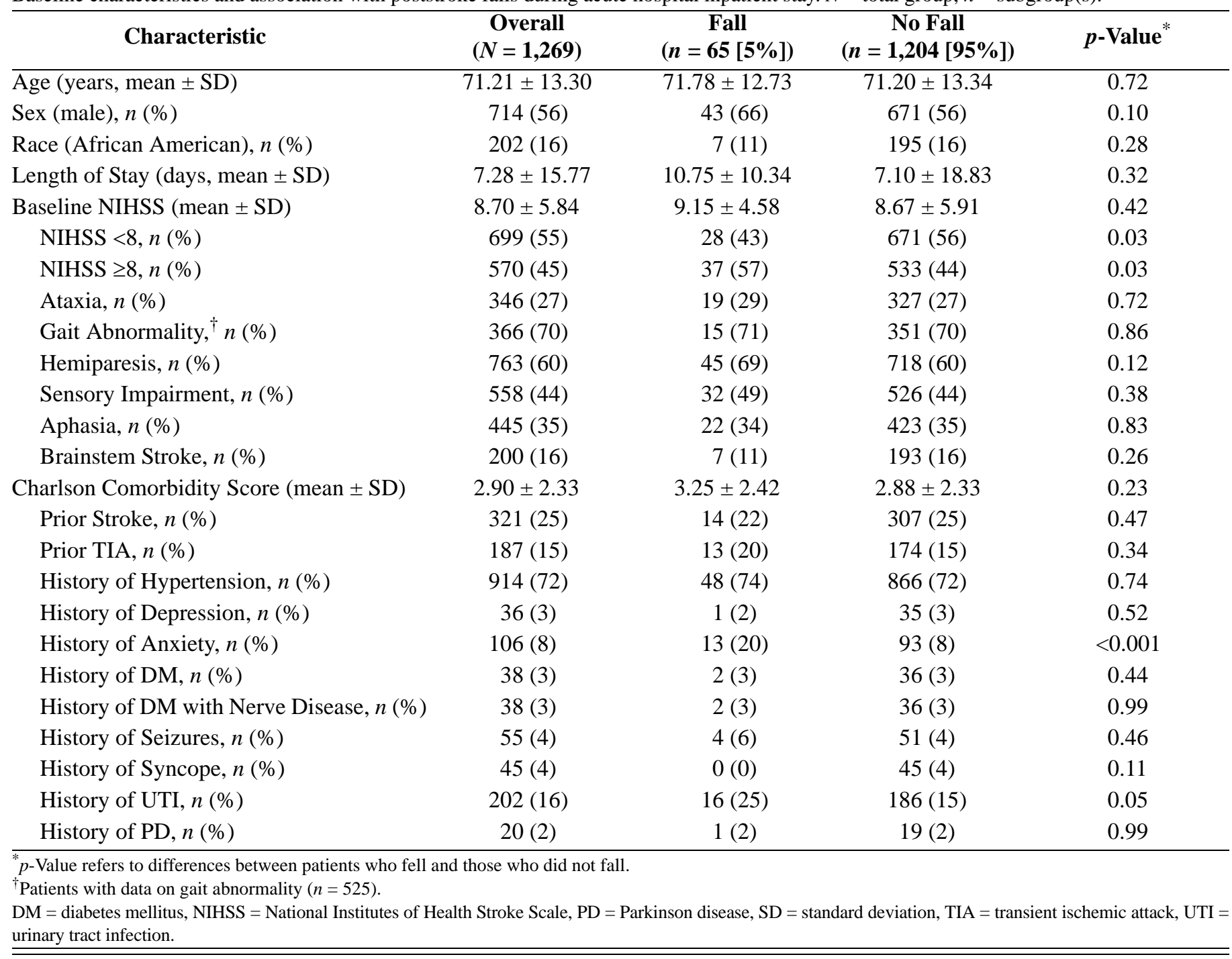


4.90, 95\% CI: 1.70-13.90). The impact factors were 0.19 for stroke severity and 0.20 for anxiety.

\section{Functional Status}

Among the 950 patients who were independent in ADLs prestroke, we considered 614 (65\%) to have a loss of functional status at the time of discharge from the acute hospital inpatient setting (Table 3). Patients with a loss of functional status at discharge were more likely to have sustained a fall than patients who remained independent in ADLs at the time of discharge ( $7 \%$ vs $1 \%, p<0.001$ ).

We associated age, sex, NIHSS $>8$, ataxia, aphasia, gait abnormality, brainstem stroke location, past stroke, history of anxiety, history of UTI, or history of syncope, and a fall in the hospital with a loss of functional status in the bivariate analysis. Medication use was not different

Table 2.

Factors independently associated with poststroke falls in acute hospital setting.

\begin{tabular}{lcr}
\hline \multicolumn{1}{c}{ Variable } & Adjusted Odds Ratio (95\% CI) & Impact Factor \\
\hline NIHSS $\geq 8$ (reference, $<8)$ & $3.63(1.46-9.00)$ & 0.19 \\
History of Anxiety (reference, no anxiety) & $4.90(1.70-13.90)$ & 0.20
\end{tabular}

Note: Adjustment variables include stroke severity (NIHSS $\geq 8$ ), gait abnormalities, Charleson Comorbidities index, history of anxiety, and history of urinary tract infection. $\mathrm{CI}=$ confidence interval, NIHSS $=$ National Institutes of Health Stroke Scale.

Table 3.

Characteristics of patients who were independent in function prestroke and association of poststroke loss of functional status ( $n=950)$.

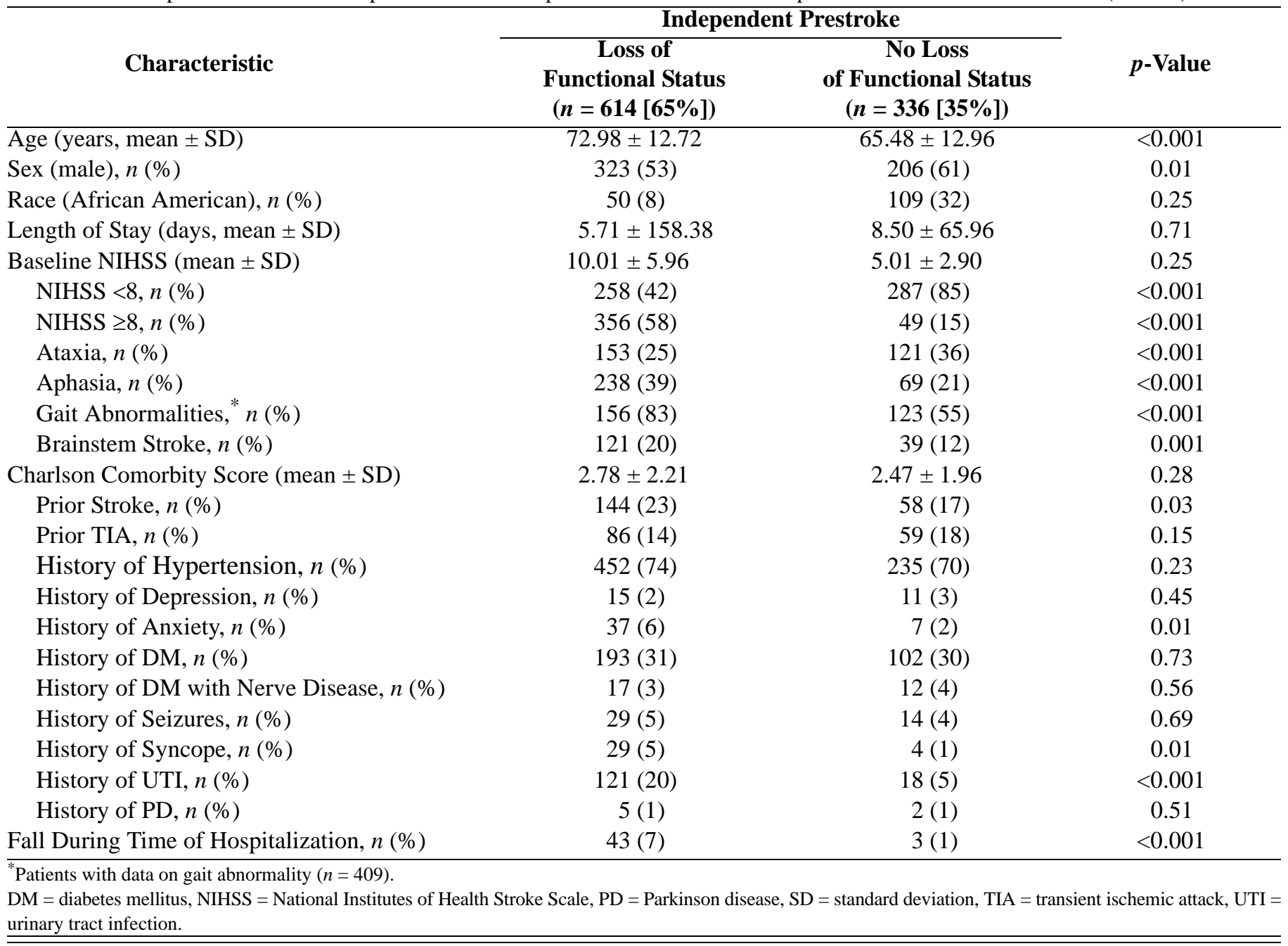


between those with and without a fall. Falls were independently associated with a loss of functional status (adjusted OR $=9.85,95 \%$ CI: $1.22-79.75$ ) even after adjusting for age in years (adjusted OR $=1.04,95 \% \mathrm{CI}$ : $1.02-1.06$ ), moderate to severe stroke severity (NIHSS $\geq 8$ ) (adjusted OR $=4.97$, 95\% CI: 2.66-9.30), gait abnormality (adjusted OR $=4.14,95 \%$ CI: 2.45-6.98), and past stroke (adjusted OR $=1.78,95 \%$ CI: 1.04-3.06) (Table 4). The impact factors were 0.08 for falls, 0.19 for age, 0.22 for stroke severity, 0.24 for gait abnormality, and 0.07 for past stroke.

\section{DISCUSSION}

We found that 5 percent of patients with an ischemic stroke fell during the acute inpatient hospitalization and that increased stroke severity and history of anxiety were independently associated with falls. Additionally, we found that falls during the acute inpatient setting were independently associated with a loss of functional status after stroke.

While several studies have described fall epidemiology during the poststroke rehabilitation period, few studies have examined poststroke falls in the acute inpatient hospital setting before discharge home or to rehabilitation. In 1996, Davenport et al. found that 22 percent of patients fell during the acute hospitalization; however, the average length of stay was 37 days, far more than our mean of 7.28 days for the entire sample [6]. More recently, Holloway et al. assessed safety concerns after stroke during the acute stay [27]. They found that 6 percent of those with ischemic stroke fell, but that people with a safety complication had a mean stay of 21 days, compared with those without a safety event who were in the acute setting for an average of 7 days [27]. While we found a comparable 5 percent fall rate in our poststroke acute population, our average length of stay for the group who sustained a fall was only 10.75 days and only 7.28 days for the entire sample. Based on our observed rate, this translates to a fall rate of 2.67 per patient per year ([65 falls/1,269 in sample]/[7 days/365 days of the year] or $0.0512 / 0.01917)$. This rate indicates a need for action and prevention during this early time after stroke.

Suzuki et al. and Teasell et al. found that nearly half of all patients with stroke fell during inpatient rehabilitation [19-20]. Recently, Czernuszenko and Cztonkowska explored fall risks for patients with stroke during inpatient rehabilitation [39]. They found that 16 percent of their sample fell during the inpatient rehabilitation hospitalization and that severe stroke-related disability was independently associated with fall rates. In contrast to our study, their sample's time since stroke was much higher: median $=36.5$ days and mean $\pm \mathrm{SD}=124.8 \pm 334.0$ days .

Existing research indicates that falls remain an issue after discharge [3-4] and still at 10 years poststroke $[13,40]$. In 2008, Weerdesteyn et al. reviewed the literature regarding poststroke falls and found a high fall incidence rate after discharge from stroke care: between 1.4 and 5.0 falls each person-year [41].

Our results indicate that falls are important even before patients transition to rehabilitation, and we suggest that fall prevention should be addressed immediately after the stroke. We encourage each patient with stroke to be screened for falls, but if that is not possible, our results indicate that special resources should be allocated for screening and treatment to anyone with an NIHSS $\geq 8$. Those who screen positive for being at risk for falls could then have fall prevention programming initiated while they are still in the acute inpatient hospitalization period. If fall prevention programming is begun before rehabilitation is started, it may allow for decreased falls as well as

Table 4.

Factors independently associated with loss in functional status.

\begin{tabular}{lcc}
\hline \multicolumn{1}{c}{ Variable } & Adjusted Odds Ratio (95\% CI) & Impact Factor \\
\hline Fall During Hospital Stay (reference, no falls) & $9.85(1.22-79.75)$ & 0.08 \\
Age (years) & $1.04(1.02-1.06)$ & 0.19 \\
NIHSS $\geq 8$ (reference, $<8)$ & $4.97(2.66-9.30)$ & 0.22 \\
Gait Abnormality (reference, no gait abnormality) & $4.14(2.45-6.98)$ & 0.24 \\
Past Stroke (reference, no past stroke) & $1.78(1.04-3.06)$ & 0.07 \\
Note: Adjustment variables include age, sex, NIHSS $\geq 8$, ataxia, aphasia, gait abnormality, brainstem stroke location, past stroke, history of anxiety, history of uri- \\
nary tract infection or syncope, and fall in hospital. \\
CI = confidence interval, NIHSS = National Institutes of Health Stroke Scale. \\
\hline \hline
\end{tabular}


for enhanced recovery during the rehabilitation period; patients with stroke may be less fearful of a future fall, and if therapists can continue rather than initiate fall prevention training, they may be able to focus more time on recovery efforts. That being said, note that in their recent review of the poststroke falls literature, Weerdesteyn et al. stated that some falls after stroke may be inevitable and that fall prevention programming, while effective in improving balance and strength, has not negated poststroke fall risk [41].

History of anxiety was an independent predictor of falls in the acute hospital inpatient setting. The mechanism by which a history of anxiety confers fall risk is not clear. We examined whether psychotropic medications (especially benzodiazepines, which may be given to patients with a history of anxiety) might be associated with falls. We found no relationship between classes of medication used at the time of admission and fall risk in this dataset. Certainly our results are in accord with the data from a pilot study showing that the development of fear of falling was highly associated with anxiety after stroke and that both fear of falling and anxiety are related to poststroke activity restriction [42]. Our results indicate that anxiety was related to both a fall in the acute hospital inpatient setting and a loss of ADL functional status. Future research should explore the roles that a history of anxiety and anxiety symptomology play in poststroke outcomes.

Our finding that 5 percent of patients with stroke fell in the acute hospital inpatient setting is likely to underrepresent the burden of falls in this setting because we relied entirely on the medical record for documentation of fall events. Despite this relatively low prevalence, we associated falls with poor patient outcomes (i.e., loss of functional status). Tinetti and Williams have reported that falls and fall-related injuries are associated with activity restriction, which is defined as reductions in ADLs, IADLs, and social participation [11]. Therefore, activity restriction may be a significant negative response related both to stroke and to poststroke falls. Health and functional status, healthcare use, and overall quality of life and life satisfaction are all influenced by activity restriction [43-44]. Although the relationship between falls and loss of functional status appears robust (adjusted OR = 9.85), a review of the impact factors for each of the variables in the multivariable model suggested that, as expected, both age and stroke severity have a stronger association with loss of functional status than do inhospital falls.

Although we were able to determine a relationship between falls and a loss of function, we were not able to address other important consequences of poststroke falls, such as increased risk of hip fracture, future falls, further reductions in function, increased anxiety and depression, development of fear of falling, or death [45-48]. Future research should examine the long-term sequelae of falls during the acute setting and develop effective interventions to best address stroke-related fall risk factors during all periods of poststroke hospitalization and rehabilitation.

Several limitations of this study should be described. First, we collected all data retrospectively and included only those falls that were documented in the medical record in this study. While we reviewed all notes from the medical record, we could have missed a fall reported in the record. The retrospective design of this study likely resulted in an underestimate of the true fall rate and also did not allow us to evaluate the role of standardized fall risk assessment. Moreover, we could not evaluate potential fall risks that are recorded routinely in the medical record. Also, differences may exist in hospital reporting of falls. We are not able to describe the prevalence or consequences of "near-fall" events. We have found selfreport of near-falls in the hospital to be a predictor of poststroke falls during the first 12 months after discharge [49].

Second, although we can demonstrate a relationship between acute hospital inpatient falls and a loss of functional status, these data cannot provide causal evidence regarding the relationship between a fall or multiple falls and poststroke outcomes. While we can demonstrate that falls happened in this acute inpatient population, we do not know the timing of the fall during the acute hospitalization, thus our results can only suggest that falls may be associated with poststroke declines in functional status. Fall prevention strategies are warranted in any event.

Third, we did not include in this analysis patients who resided in a skilled nursing facility at the time of their stroke onset. Both the prevalence of falls and the predictors of falls in such patients may differ from our findings. Given that the majority of patients with stroke live at home at the time of stroke onset, these findings should be generalizable to the majority of patients with stroke. We did exclude those who were in a coma or who had an NIHSS $\geq 18$ to minimize the inclusion of those who were not mobile after stroke. 
Fourth, fall risks are multifactorial [15] and some preexisting risk factors were not available in the data for analysis. While we included important available risk factors into our analysis (age, stroke severity, sex, anxiety, stroke location, Parkinson disease, etc.), other fall risks factors (such as fear of falling, environmental factors, gait speed, foot problems, and hip or knee arthritis) were not available and thus we did not include them in this analysis.

Fifth, this study only included patients with ischemic stroke. Thus, it does not represent all patients with acute stroke. However, the majority of sustained strokes are indeed ischemic strokes.

Finally, this study evaluated short-term outcomes of patients with stroke who fall during the acute inpatient hospitalization. Future studies should examine the longterm outcomes (both recurrent falls and loss of function status) for patients who fall during the acute inpatient hospitalization.

\section{CONCLUSIONS}

We found that poststroke falls in the acute hospital inpatient setting, albeit relatively uncommon in this sample, are associated with adverse patient outcomes. Fall prevention programming uses time, money, and other resources, and takes time away from other rehabilitation efforts. Because the NIHSS or retrospective NIHSS is easily available for all patients with stroke, a therapist can identify those most at risk for a future fall while still in the acute setting. Stroke severity, specifically NIHSS $\geq 8$, may be a clinically useful way to identify patients with stroke who are at greatest risk of falling. Given the association between falls and poor patient outcomes, rehabilitation and other interventions should be implemented to prevent falls poststroke.

\section{ACKNOWLEDGMENTS}

\section{Author Contributions:}

Study concept and design: C. K. Wells, D. M. Bravata. Acquisition of data: D. M. Bravata, J. Concato, M. I. Dallas, A. C. Lo, A. J. Peixoto, M. Gorman, J. L. Boice, F. Struve, V. McClain. Analysis and interpretation of data: A. A. Schmid, D. M. Bravata. Drafting of manuscript: A. A. Schmid, D. M. Bravata. Critical revision of manuscript for important intellectual content: A. A. Schmid, C. K. Wells, D. M. Bravata, J. Concato, M. I. Dallas, A. C. Lo, S. E. Nadeau, L. S. Williams.
Statistical analysis: A. A. Schmid, D. M. Bravata. Obtained funding: D. M. Bravata, L. S. Williams.

Administrative, technical, or material support: D. M. Bravata, F. Struve.

Study supervision: D. M. Bravata.

Financial Disclosures: The authors have declared that no competing interests exist.

Funding/Support: This material was based on work supported by a Career Development Award from the VA Rehabilitation Research and Development Service to Dr. Schmid (grant CDA D6174W); the VA Health Services Research and Development Service (grant IIR-01104-3), the Max Patterson Stroke Research Fund at Yale University; an Advanced Career Development Award from the VA Health Services Research and Development Service to Dr. Bravata; and the Robert Wood Johnson Generalist Physician Faculty Scholar Program. Dr. Schmid is now also with the Regenstrief Institute, Inc, Indianapolis, Indiana.

Institutional Review: We received institutional review board approval from VA Research and Development, VA Connecticut Healthcare System, West Haven, Connecticut; Indiana University, Indianapolis, Indiana; and Yale University, New Haven, Connecticut.

Participant Follow-Up: The authors do not plan to notify the study subjects of the publication of this article because of a lack of contact information.

\section{REFERENCES}

1. Writing Group Members. Lloyd-Jones D, Adams RJ, Brown TM, Carnethon M, Dai S, De Simone G, Ferguson TB, Ford E, Furie K, Gillespie C, Go A, Greenlund K, Haase N, Hailpern S, Ho PM, Howard V, Kissela B, Kittner S, Lackland D, Lisabeth L, Marelli A, McDermott MM, Meigs J, Mozaffarian D, Mussolino M, Nichol G, Roger VL, Rosamond W, Sacco R, Sorlie P, Stafford R, Thom T, Wasserthiel-Smoller S, Wong ND, Wylie-Rosett J; American Heart Association Statistics Committee and Stroke Statistics Subcommittee. Heart disease and stroke statistics2010 update: A report from the American Heart Association. Circulation. 2010;121(7):e46-215. [PMID: 20019324]

2. Pulaski KH. Adult neurological dysfunction. In: Crepeau EB, Cohn ES, Boyt Schell BA, editors. Willard \& Spackman's occupational therapy. 10th ed. Philadelphia (PA): Lippincott; 2003. p. 767-88.

3. Yates JS, Lai SM, Duncan PW, Studenski S. Falls in community-dwelling stroke survivors: An accumulated impairments model. J Rehabil Res Dev. 2002;39(3):385-94. [PMID: 12173758]

4. Forster A, Young J. Incidence and consequences of falls due to stroke: A systematic inquiry. BMJ. 1995;311(6997): 83-86. [PMID: 7613406$]$

5. Hyndman D, Ashburn A, Stack E. Fall events among people with stroke living in the community: Circumstances of 
falls and characteristics of fallers. Arch Phys Med Rehabil. 2002;83(2):165-70. [PMID: 11833018]

DOI:10.1053/apmr.2002.28030

6. Davenport RJ, Dennis MS, Wellwood I, Warlow CP. Complications after acute stroke. Stroke. 1996;27(3):415-20. [PMID: 8610305]

7. Tinetti ME, Speechley M, Ginter SF. Risk factors for falls among elderly persons living in the community. N Engl J Med. 1988;319(26):1701-7. [PMID: 3205267]

8. Donald IP, Bulpitt CJ. The prognosis of falls in elderly people living at home. Age Ageing. 1999;28(2):121-25.

[PMID: 10350407$]$ DOI:10.1093/ageing/28.2.121

9. Sterling DA, O’Connor JA, Bonadies J. Geriatric falls: Injury severity is high and disproportionate to mechanism. J Trauma. 2001;50(1):116-19. [PMID: 11231681] DOI:10.1097/00005373-200101000-00021

10. Rubenstein LZ. Falls in older people: Epidemiology, risk factors and strategies for prevention. Age Ageing. 2006; 35(Suppl 2):ii37-ii41. [PMID: 16926202] DOI:10.1093/ageing/afl084

11. Tinetti ME, Williams CS. The effect of falls and fall injuries on functioning in community-dwelling older persons. J Gerentol A Biol Sci Med Sci. 1998;53(2):M112-M19.

[PMID: 9520917]

12. Hyndman D, Ashburn A. People with stroke living in the community: Attention deficits, balance, ADL ability and falls. Disabil Rehabil. 2003;25(15):817-22. [PMID: 12851091] DOI:10.1080/0963828031000122221

13. Jørgensen L, Engstad T, Jacobsen BK. Higher incidence of falls in long-term stroke survivors than in population controls: Depressive symptoms predict falls after stroke. Stroke. 2002;33(2):542-47. [PMID: 11823667] DOI:10.1161/hs0202.102375

14. Ramnemark A, Nyberg L, Borssén B, Olsson T, Gustafson Y. Fractures after stroke. Osteoporos Int. 1998;8(1):92-95. [PMID: 9692083] DOI:10.1007/s001980050053

15. Nuffield Institute for Health, University of Leeds and NHS Centre for Reviews and Dissemination. Preventing falls and subsequent injury in older people. Effective Healthcare. 1996;2(4):1-16.

16. Tinetti ME, Williams TF, Mayewski R. Fall risk index for elderly patients based on number of chronic disabilities. Am J Med. 1986;80(3):429-34. [PMID: 3953620] DOI:10.1016/0002-9343(86)90717-5

17. Thurman DJ, Stevens JA, Rao JK; Quality Standards Subcommittee of the American Academy of Neurology. Practice parameter: Assessing patients in a neurology practice for risk of falls (an evidence-based review): Report of the Quality Standards Subcommittee of the American Academy of Neurology. Neurology. 2008;70(6):473-79.

\section{[PMID: 18250292]}

DOI:10.1212/01.wnl.0000299085.18976.20

18. Lee JE, Stokic DS. Risk factors for falls during inpatient rehabilitation. Am J Phys Med Rehabil. 2008;87(5):34151,422. [PMID: 18427218$]$

19. Suzuki T, Sonoda S, Misawa K, Saitoh E, Shimizu Y, Kotake T. Incidence and consequence of falls in inpatient rehabilitation of stroke patients. Exp Aging Res. 2005; 31(4):457-69. [PMID: 16147463]

DOI:10.1080/03610730500206881

20. Teasell R, McRae M, Foley N, Bhardwaj A. The incidence and consequences of falls in stroke patients during inpatient rehabilitation: Factors associated with high risk. Arch Phys Med Rehabil. 2002;83(3):329-33. [PMID: 11887112] DOI:10.1053/apmr.2002.29623

21. Sze KH, Wong E, Leung HY, Woo J. Falls among Chinese stroke patients during rehabilitation. Arch Phys Med Rehabil. 2001;82(9):1219-25. [PMID: 11552194] DOI:10.1053/apmr.2001.25094

22. Mayo NE, Korner-Bitensky N, Becker R, Georges P. Predicting falls among patients in a rehabilitation hospital. Am J Phys Med Rehabil. 1989;68(3):139-46. [PMID: 2730782] DOI:10.1097/00002060-198906000-00008

23. Campbell AJ, Borrie MJ, Spears GF. Risk factors for falls in a community-based prospective study of people 70 years and older. J Gerontol. 1989;44:M112-M17.

[PMID: 2738307]

24. O’Loughlin JL, Robitaille Y, Boivin JF, Suissa S. Incidence of and risk factors for falls and injurious falls among the community-dwelling elderly. Am J Epidemiol. 1993;137(3): 342-54. [PMID: 8452142]

25. Mackintosh SF, Hill KD, Dodd KJ, Goldie PA, Culham EG. Balance score and a history of falls in hospital predict recurrent falls in the 6 months following stroke rehabilitation. Arch Phys Med Rehabil. 2006;87(12):1583-89. [PMID: 17141637]

DOI:10.1016/j.apmr.2006.09.004

26. Tutuarima JA, Van der Meulen JH, De Haan RJ, Van Straten A, Limburg M. Risk factors for falls of hospitalized stroke patients. Stroke. 1997;28(2):297-301.

[PMID: 9040678]

27. Holloway RG, Tuttle D, Baird T, Skelton WK. The safety of hospital stroke care. Neurology. 2007;68(8):550-55. [PMID: 17310024] DOI:10.1212/01.wnl.0000254992.39919.2e

28. Bravata DM, Wells CK, Lo AC, Nadeau SE, Melillo J, Chodkowski D, Struve F, Williams LS, Peixoto AJ, Gorman M, Goel P, Acompora G, McClain V, Ranjbar N, Tabereaux PB, Boice JL, Jacewicz M, Concato J. Processes of care associated with acute stroke outcomes. Arch Intern Med. 2010;170(9):804-10. [PMID: 20458088]

DOI:10.1001/archinternmed.2010.92 
29. Luukinen H, Koski K, Laippala P, Kivela SL. Risk factors for recurrent falls in the elderly in long-term institutional care. Public Health. 1995;109(1):57-65. [PMID: 7871147] DOI:10.1016/S0033-3506(95)80076-X

30. Charlson ME, Pompei P, Ales KL, MacKenzie CR. A new method of classifying prognostic comorbidity in longitudinal studies: Development and validation. J Chronic Dis. 1987; 40(5):373-83. [PMID: 3558716] DOI:10.1016/0021-9681(87)90171-8

31. Fletcher PC, Hirdes JP. Risk factors for serious falls among community-based seniors: Results from the National Population Health Survey. Can J Aging. 2002;21(1):103-16.

32. Albanese MA, Clarke WR, Adams HP Jr, Woolson RF. Ensuring reliability of outcome measures in multicenter clinical trials of treatments for acute ischemic stroke. The program developed for the Trial of Org 10172 in Acute Stroke Treatment (TOAST). Stroke. 1994;25(9):1746-51. [PMID: 8073453]

33. Lyden P, Brott T, Tilley B, Welch KM, Mascha EJ, Levine S, Haley EC, Grotta J, Marler J. Improved reliability of the NIH Stroke Scale using video training. NINDS TPA Stroke Study Group. Stroke. 1994;25(11):2220-26.

[PMID: 7974549]

34. Williams LS, Yilmaz EY, Lopez-Yunez AM. Retrospective assessment of initial stroke severity with the NIH Stroke Scale. Stroke. 2000;31(4):858-62. [PMID: 10753988]

35. Brott T, Adams HP Jr, Olinger CP, Marler JR, Barsan WG, Biller J, Spilker J, Holleran R, Eberle R, Hertzberg V. Measurements of acute cerebral infarction: A clinical examination scale. Stroke. 1989;20(7):864-70. [PMID: 2749846$]$

36. Clark WM, Williams BJ, Selzer KA, Zweifler RM, Sabounjian LA, Gammans RE. A randomized efficacy trial of citicoline in patients with acute ischemic stroke. Stroke. 1999;30(12):2592-97. [PMID: 10582983]

37. Concato J, Peduzzi P, Holford TR, Feinstein AR. Importance of events per independent variable in proportional hazards analysis. I. Background, goals, and general strategy. J Clin Epidemiol. 1995;48(12):1495-1501. [PMID: 8543963] DOI:10.1016/0895-4356(95)00510-2

38. Feinstein AR. Multivariable analysis: An introduction. New Haven (CT): Yale University Press; 1996.

39. Czernuszenko A, Cztonkowska A. Risk factors for falls in stroke patients during inpatient rehabilitation. Clin Rehabil. 2009;23(2):176-88. [PMID: 19164405] DOI:10.1177/0269215508098894

40. Ugur C, Gücüyener D, Uzuner N, Ozkan S, Ozdemir G. Characteristics of falling in patients with stroke. J Neurol Neurosurg Psychiatry. 2000;69(5):649-51.

[PMID: 11032620]

DOI:10.1136/jnnp.69.5.649
41. Weerdesteyn V, De Niet M, Van Duijnhoven HJ, Geurts AC. Falls in individuals with stroke. J Rehabil Res Dev. 2008;45(8):1195-1213. [PMID: 19235120]

DOI:10.1682/JRRD.2007.09.0145

42. Schmid AA, Acuff M, Doster K, Gwaltney-Duiser A, Whitaker A, Damush T, Williams L, Hendrie H. Poststroke fear of falling in the hospital setting. Top Stroke Rehabil. 2009;16(5):357-66. [PMID: 19903654]

DOI:10.1310/tsr1605-357

43. Gill TM, Desai MM, Gahbauer EA, Holford TR, Williams CS. Restricted activity among community-living older persons: Incidence, precipitants, and health care utilization. Ann Intern Med. 2001;135(5):313-21. [PMID: 11529694$]$

44. Gill TM, Allore HG, Holford TR, Guo Z. Hospitalization, restricted activity, and the development of disability among older persons. JAMA. 2004;292(17):2115-24.

[PMID: 15523072]

DOI:10.1001/jama.292.17.2115

45. Chiu KY, Pun WK, Luk KD, Chow SP. A prospective study on hip fractures in patients with previous cerebralvascular accidents. Injury. 1992;23(5):297-99.

[PMID: 1644455]

DOI:10.1016/0020-1383(92)90171-N

46. Hyndman D, Ashburn A, Stack E. Fall events among people with stroke living in the community: Circumstances of falls and characteristics of fallers. Arch Phys Med Rehabil. 2002;83(2):165-70. [PMID: 11833018]

DOI:10.1053/apmr.2002.28030

47. Schmid AA, Rittman M. Consequences of poststroke falls: Activity limitation, increased dependence, and the development of fear of falling. Am J Occup Ther. 2009;63(3):310-16. [PMID: 19522139]

48. Ramnemark A, Nilsson M, Borssen B, Gustafson Y. Stroke, a major and increasing risk factor for femoral neck fracture. Stroke. 2000;31(7):1572-77. [PMID: 10884456]

49. Ashburn A, Hyndman D, Pickering R, Yardley L, Harris S. Predicting people with stroke at risk of falls. Age Ageing. 2008;37(3):270-76. [PMID: 18456791]

DOI:10.1093/ageing/afn066

Submitted for publication August 22, 2009. Accepted in revised form April 7, 2010.

This article and any supplementary material should be cited as follows:

Schmid AA, Wells CK, Concato J, Dallas MI, Lo AC, Nadeau SE, Williams LS, Peixoto AJ, Gorman M, Boice JL, Struve F, McClain V, Bravata DM. Prevalence, preditors, and outcomes of postroke falls in acute hospital setting. J Rehabil Res Dev. 2009;47(6):553-62.

DOI:10.1682/JRRD.2009.08.0133 